\title{
Self-heating function of carbon nanofiber cement pastes
}

\author{
O. Galao ${ }^{\text {a }}$ F.J. Baeza ${ }^{\text {a }}$, E. Zornoza ${ }^{\text {a }}$ P. Garcés ${ }^{\mathrm{a}} \bowtie$ \\ a. University of Alicante, Alicante (Spain) \\ \pedro.garces@ua.es
}

Received 27 February 2013

Accepted 9 December 2013

Available on line 26 May 2014

\begin{abstract}
The viability of carbon nanofiber (CNF) composites in cement matrices as a self-heating material is reported in this paper. This functional application would allow the use of CNF cement composites as a heating element in buildings, or for deicing pavements of civil engineering transport infrastructures, such as highways or airport runways.

Cement pastes with the addition of different CNF dosages (from 0 to $5 \%$ by cement mass) have been prepared. Afterwards, tests were run at different fixed voltages $(50,100$ and $150 \mathrm{~V})$, and the temperature of the specimens was registered. Also the possibility of using a casting method like shotcrete, instead of just pouring the fresh mix into the mild (with no system's efficiency loss expected) was studied.

Temperatures up to $138{ }^{\circ} \mathrm{C}$ were registered during shotcrete- $5 \% \mathrm{CNF}$ cement paste tests (showing initial $10^{\circ} \mathrm{C} / \mathrm{min}$ heating rates). However a minimum voltage was required in order to achieve a proper system functioning.
\end{abstract}

KEYWORDS: Cement; Carbon nanofibers; Self-heating

Citation / Citar como: Galao, O.; Baeza, F.J.; Zornoza, E.; Garcés, P. (2014) Self-heating function of carbon nanofiber cement pastes Mater. Construcc. 64 [314], e015 http://dx.doi.org/10.3989/mc.2014.01713.

RESUMEN: Función de calefacción en pastas de cemento con adición de nanofibras de carbono. En este artículo se estudia la viabilidad del uso de matrices cementicias con adición de nanofibras de carbono (NFC) como elementos calefactores. Esto permitiría aumentar la temperatura de estancias en edificación o el deshielo de pavimentos en obras civiles.

Se han fabricado pastas de cemento con distintas dosificaciones de NFC $(0,1,2$ y $5 \%$ respecto masa del cemento) y sometidas al paso de corriente continua a distintos potenciales fijos (50, 100 y $150 \mathrm{~V})$, mientras se controlaba la temperatura en distintos puntos. Se ha estudiado la viabilidad de utilizar la proyección de la pasta fresca como método de puesta en obra, sin perjudicar la eficiencia del sistema.

Se consiguieron temperaturas de hasta $138^{\circ} \mathrm{C}$ (con velocidades iniciales de $10{ }^{\circ} \mathrm{C} / \mathrm{min}$ ) para pasta proyectada con $5 \%$ NFC. Además se ha detectado la necesidad de un potencial mínimo para que la densidad de corriente resultante sea suficiente para producir el efecto esperado.

PALABRAS CLAVE: Cemento; Nanofibras de carbono; Calefacción

Copyright: (C) 2014 CSIC. This is an open-access article distributed under the terms of the Creative Commons Attribution-Non Commercial (by-nc) Spain 3.0 License. 


\section{INTRODUCTION}

Concrete's main application is as a structural material. Despite cement's dielectric properties, which make it a bad electrical conductor, the addition of conductive admixtures (carbon fibers, nanofibers or nanotubes, graphite powder, steel fibers, etc.) can transform concrete into a good electrical conductor (1-2). And so, new functional applications are available, besides just the structural, so regular concrete becomes a multifunctional conductive concrete (3-4). These functional properties are related to self-heating (e.g. for deicing or room heating) (5-15), strain or damage sensing (16-17), EMI shielding (18-20), or as an anode in the electrochemical chloride extraction technique (21-23) or cathodic protection (24-25).

The self-heating application is directly related to the increase of the composite's thermal and electrical conductivities (8). Just like any electrical resistance, if a constant electrical current is applied to multifunctional cement composites (which electrical resistivity has been diminished due to conductive admixtures) a part of the energy is transformed into heat; hence the specimen's temperature increases due to Joule effect (7). This property would be very useful if these conductive composites were used as heating or deicing elements $(5-6,15)$.

In the late 90's early studies regarding the thermal applications of cement pastes and mortars with carbon fibers addition can be found, e.g. temperature sensors (paste acting as a thermistor) or Seebeck effect. Furthermore the electrical resistivity and specific heart of these materials were reported. Both parameters are essential to develop heating elements or heat accumulators respectively $(7-9,11)$.

Other researchers focused their investigation, regarding self-heating concrete, on the optimization of concrete's dosages with the addition of carbon fibers and steel fibers (5-6). This group even built a road bridge's deck using conductive concrete with carbon admixtures, which was later used successfully as a deicing device during several snowstorms, showing a mean power consumption of $452 \mathrm{~W} / \mathrm{m}^{2}$ (12). This application removing the ice layer on transport infrastructures (e.g. highways, road bridges or airport runways) will definitely improve transport safety, without endanger the structural durability, as other usual deicing chemicals do. Several deicing methods that are currently being used are based on chemical agents that are aggressive to concrete or steel in civil infrastructures (bridges, tunnels, airports).

Yehia and Tuan (5) reported a comparison between different traditional deicing methods (either chemicals or heating devices) and a steel fiber concrete used for the same purpose. Amongst the available chemical products, sodium chloride (the cheapest salt used nowadays) can be used in temperatures over
$-10{ }^{\circ} \mathrm{C}$, while calcium chloride can be used up to $-25^{\circ} \mathrm{C}$ (but it is ten times more expensive). Other products such as calcium magnesium acetate, urea, magnesium chloride, formamide or tetrapotassium pyrophosphate do not improve the former's effectiveness and their costs are also higher. However, the main problem associated with chloride salts is steel rebars corrosion, one of the main concrete's pathologies and an environmental issue too.

The alternative technique of mechanically removing the ice results obviously in a harder, more expensive and slower work. Especially compared to electrical deicing of self-heating materials, which is a continuous and simple method. Heating techniques come as an alternative to deicing chemicals. The first possibility would be infrared lamps, which is a low cost system but with poor durability and higher maintenance requirements in structures like bridges or airports. Electrical heating cable is another alternative with durability issues and higher power consumption, but cheaper than infrared solutions. Hot water or heating gas systems come both at higher power consumption, besides their problems to be used in isolated structures, such as road bridges. Finally, the energy requirements of a conductive concrete overlay are similar, and the total costs, considering maintenance and construction, will be lower than the other heating systems (5).

Over the last decades several reports have been focused on conductive admixtures in different matrices (1-36). Recently carbon nanotubes (CNT) and carbon nanofibers (CNF) have shown very good mechanical, thermal and electrical performances (28-33). Carbon materials have a high thermal conductivity (however not as much as metals), a low thermal coefficient (lower than metals) and they are also very resistant to corrosion (8). All these properties are desirable in multifunctional cement composites, and carbon materials are therefore suitable as conductive admixtures. The new generation of carbon nano-filaments show excellent mechanical, electrical and thermal properties, and have been used successfully in polymer matrices (29-32). These filaments, either CNF or CNT, could be an alternative or a complement to traditional carbon fibers. Furthermore, they can be also the foundation of the next generation of smart structures and multifunctional high performance cement composites.

A recent study reported a deicing system, in which a CNF polymeric composite was used as heating source and combined with a CNT cement composite as thermal conductor (15). However, there is a lack of studies with CNF cement composites acting simultaneously as heating element and as thermal conductor. If a conductive concrete overlay was used in a conventional concrete structure, strain could be monitored (and implemented in a service life control system) (34), rooms could be heated, undesired 
electromagnetic waves could be avoided $(19,20)$, and electrochemical chloride extraction (ECE) or cathodic protection could be applied $(22,23)$. All these functional applications could be achieved at once with only one composite.

Another breakthrough in this field would be the use of shotcrete as casting method for these materials. There are several studies confirming that most functional applications are not affected by this casting alternative method, e.g. strain sensing (3) or ECE anode (23). CNF cement composites could be a real alternative once the dosage and energy consumption have been optimized, as they show good durability and good mechanical performance $(3,28,33,35)$.

This research is the first work on the capacity of CNF cement pastes as heating element. Cement paste has been selected as matrix in order to avoid other elements (aggregates) which can difficult the phenomenon analysis. Moreover, the possibility of a shotcrete like casting method is studied (due to the good results obtained previously in strain sensing and ECE researches).

\section{EXPERIMENTAL PROGRAM AND MATERIALS}

Cement pastes with different CNF additions were prepared in order to study their heating capacity. The materials used to prepare the pastes were: Portland cement type I (EN 197 CEM I 52.5 R), distilled water and carbon nanofibers (CNF) stacked-cup GANF4 type supplied by Grupo Antolín-Irausa, S.A. (Burgos, Spain), which main properties are included in Table 1.

In order to guarantee a proper CNF dispersion in the mix two different treatments were applied. First of all CNF were mechanically dispersed in the mix water using a high shear laboratory mixer. Afterwards an ultrasound treatment was applied using an ultrasound device model Hielschier UP200S. Finally all the components were mixed for 5 minutes. After 24 hours all specimens were

TABLE 1. Main properties of carbon nanofibers GANF4 type

\begin{tabular}{lll}
\hline Properties & Unit & GANF \\
\hline Fiber diameter (TEM) & $\mathrm{nm}$ & $20-80$ \\
Fiber length (SEM) & $\mu \mathrm{m}$ & $>30$ \\
Bulk density & $\mathrm{g} / \mathrm{cm}^{3}$ & $>1.97$ \\
Apparent density & $\mathrm{g} / \mathrm{cm}^{3}$ & 0.060 \\
Surface energy & $\mathrm{mJ} / \mathrm{m}^{2}$ & $\approx 100$ \\
Specific surface area BET $\left(\mathrm{N}_{2}\right)$ & $\mathrm{m} / \mathrm{g}$ & $150-200$ \\
Graphitization degree & $\%$ & $\approx 70$ \\
Electrical resistivity & $\mathrm{ohm} \cdot \mathrm{m}$ & $1 \cdot 10^{-3}$ \\
Metallic particles content & $\%$ & $6-8$ \\
\hline
\end{tabular}

demolded and kept for curing at controlled ambient room $\left(100 \% \mathrm{RH}\right.$ and $\left.20{ }^{\circ} \mathrm{C}\right)$ for 28 days until specimen's testing.

CNF dosages were $0,1,2$ and $5 \%$ by cement mass. In order to achieve the same level of workability in the fresh mix without using plasticizers the water/cement ratio (w/c) was adjusted previously by measuring the slump according to standard UNE 83258-05. All dosages showed deviations lower than $10 \%$ with respect to the control specimen with no $\mathrm{CNF}$ and a w/c ratio of 0.5 .

Testing specimens with 0,1 and $2 \% \mathrm{CNF}$ were fabricated pouring the fresh paste in a mold of internal dimensions $10 \times 10 \times 1 \mathrm{~cm}^{3} .5 \% \mathrm{CNF}$ pastes were casted as shotcrete, method which required higher amount of water in the paste $(\mathrm{w} / \mathrm{c}=1)$. In previous studies these pastes with $5 \% \mathrm{CNF}$ addition and $\mathrm{w} / \mathrm{c}=1$ were casted by the traditional method (just pouring into the mold) and showed severe shrinkage problems that made impossible their testing. Table 2 summarizes all the dosages that were prepared, including their $\mathrm{CNF}$ addition, w/c ratio and casting method.

Figure 1 includes the main dimensions of the specimens and the experimental setup. Tests consisted on applying a constant voltage between two end sides of each specimen $\left(10 \times 1 \mathrm{~cm}^{2}\right)$, which had been previously painted with conductive silver paint (Pelco conductive silver 187, from Ted Pella Inc., USA) in order to improve electrical contact between the primary electrode (stainless steel mesh $0.9 \mathrm{~mm}$ thick) and the composite. Changes in the surface temperature of the specimens were continuously registered by RTD temperature sensors type Pt100, distributed as shown in Figure 1, and connected to a data logger (model DAS-8000, Desin Instruments, Barcelona).

A digital Consort EV231 direct current source was used to fix the testing voltage, while current intensity was measured with a digital multimeter (Keithley 2002, National Instruments Inc.).

Testing voltages were fixed to 50,100 and $150 \mathrm{~V}$. All specimens were kept in controlled environment until testing $\left(20^{\circ} \mathrm{C}\right.$ and $\left.100 \% \mathrm{RH}\right)$. However, 3 specimens with 5\% CNF were kept in laboratory conditions $\left(20{ }^{\circ} \mathrm{C}\right.$ and $55 \% \mathrm{RH}$, approximately) until constant weight, repeating the same experimental tests afterwards.

TABLE 2. Water/cement ratio (w/c) and casting method corresponding to each CNF dosage

\begin{tabular}{lcc}
\hline CNF (\% by cement mass) & w/c & Casting method \\
\hline $0 \%$ & 0.35 & Poured \\
$1 \%$ & 0.42 & Poured \\
$2 \%$ & 0.50 & Poured \\
$5 \%$ & 1.00 & Shot \\
\hline
\end{tabular}




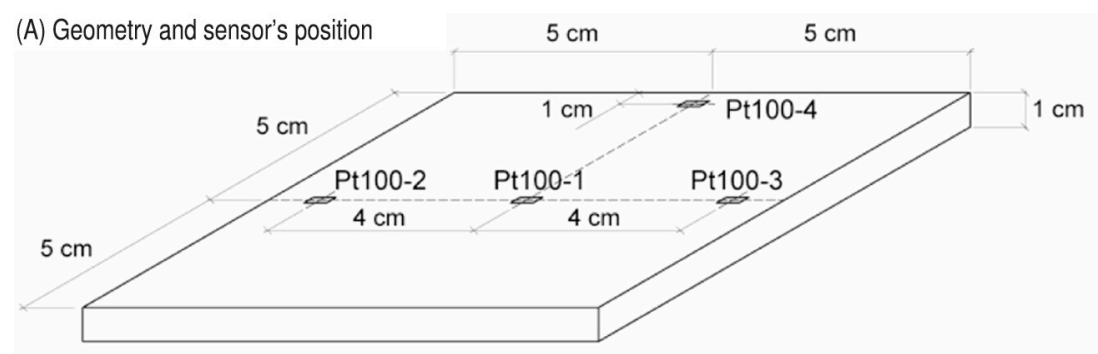

(B) Self heating experimental set up

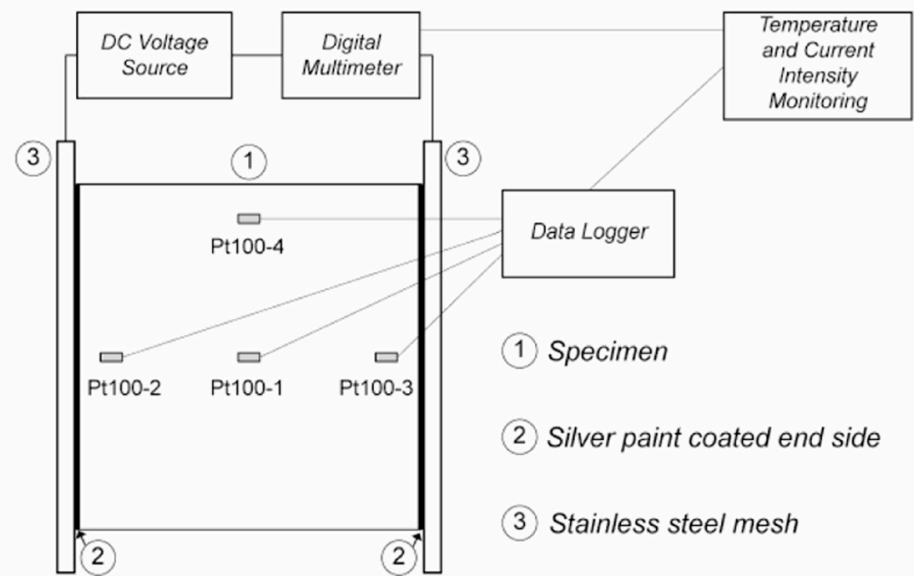

Figure 1. (A) Specimen's geometry and location of temperature sensors, Pt100. (B) Experimental set up for a self-heating test.

The following parameters were analyzed once the experimental tests were completed:

- Temperature change of the specimen's surface, temperature field homogeneity.

- Effect of CNF dosage and the testing voltage in the mean temperature increment.

- Maximum heating rates of the mean temperature.

- Electrical current behavior, i.e. changes during each test.

- Power consumption for $10{ }^{\circ} \mathrm{C}$ increase in the center point of the specimen's upper side, for different voltages.

\section{RESULTS AND DISCUSSION}

Pt-100 distribution, as included in Figure 1, allowed to automatically control the temperature gradients between points in the upper side of the specimens. One sensor was located in the center of the surface, another two were close to each electrical contact and the fourth one close to the lateral side. Moreover, this temperature distribution was compared to the images taken with a FLIR E30 thermographic camera.

A pattern was detected in the temperature's distribution, as the maximum value was measured in the center of the specimens. However heating generation was quite uniform in the specimens, heat losses were higher in the lateral sides due to the experimental setup. Moreover, no damage was detected in any electrode during tests.

Figure 2 shows two termographies taken during different tests. The temperature field is quite homogeneous and therefore the previous discussion using discrete temperature measures may be extended to all the specimens. The temperature differences between sensors were small, compared to the maximum temperatures achieved, hence the following discussion during this paper will focus on the mean temperature value (calculated with the 4 sensor's data).

\subsection{Effect of cnf dosage and voltage}

First of all, the effect of CNF dosage was considered. As an example, Figure 3 includes the results of self-heating tests for every dosage $(0,1,2$ and $5 \%$ CNF by cement mass) at $150 \mathrm{~V}$ fixed voltage and all specimens in $100 \%$ RH conditions. Each graphic includes temperature at the center point and current intensity, versus time.

Three different phases can be distinguished: a first stage where ambient temperature was measured; after a few seconds the power source was connected to the corresponding voltage; and finally 


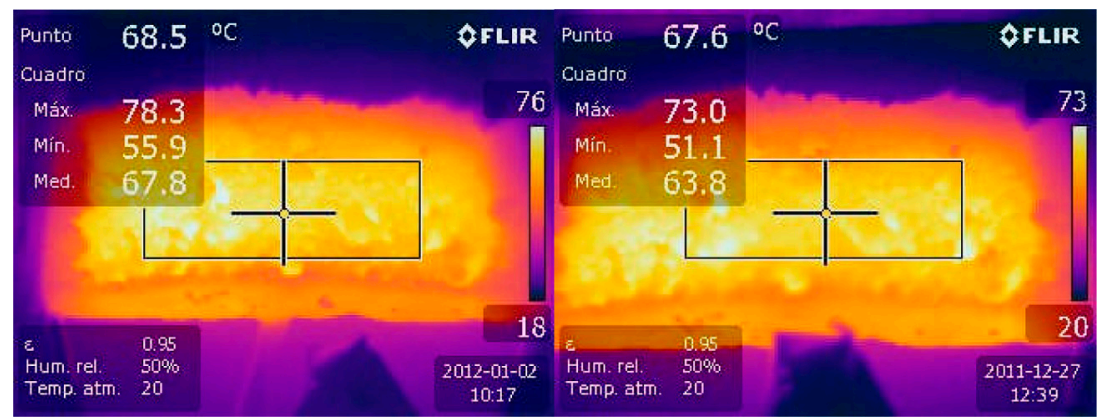

FIGURE 2. Thermography images obtained during self-heating tests of a $5 \% \mathrm{CNF}$ cement paste specimen.

the power source was disconnected after a variable period of time depending on the particular conditions of each test. Temperature monitoring did not stop until ambient temperature was reached again. All 4 sensors measures and current intensity were continuously monitored. A first conclusion, according to Figure 3 is that pastes with higher amount of $\mathrm{CNF}$ reached higher temperatures. Figure 4 shows the same variables (i.e. current intensity and temperature) for 5\% CNF specimens kept in laboratory conditions $\left(20^{\circ} \mathrm{C}\right.$ and $\left.55 \% \mathrm{RH}\right)$ until constant weight. It can be observed that the moisture loss resulted in a higher maximum temperature in the laboratory conserved specimens with respect to its $100 \% \mathrm{RH}$ counterpart (Figure 3D), when $150 \mathrm{~V}$ were applied.

Figure 5 summarizes the temperature tests results registered at the center point of the specimens (Pt100-1 in Figure 1). Three different behaviors can be observed: first of all, specimens without CNF addition, in which no temperature increase was measured; second, all 100\% RH specimens with any CNF dosage showed similar behavior; and finally $5 \% \mathrm{CNF}$ specimens kept in laboratory conditions showed much higher heating rate and the maximum temperature achieved (actually these tests were stopped for safety concerns, in order to avoid high temperature system deterioration).

The effect of the voltage was studied repeating tests at 50,100 and 150V, for all five dosages. Figure 6 includes the mean temperature increment (using all four Pt100) for each CNF dosage versus the fixed voltage during each test. As a general rule, higher voltages led to higher temperatures, and obviously to higher current intensity levels.

The range of temperatures reached during this research (up to $138^{\circ} \mathrm{C}$ ) is far beyond those reported in prior work with cement pastes and different conductive fibers (9), in which the maximum temperatures were 60,56 and $24{ }^{\circ} \mathrm{C}$ for cement pastes with $0.7 \mathrm{vol} \%$ steel fibers, $1 \mathrm{vol} \%$ carbon fibers and $37 \mathrm{vol} \%$ graphite powder respectively. The $138{ }^{\circ} \mathrm{C}$ of the current research is actually similar to a continuous carbon fiber mat in organic conglomerate
(11). Other cement materials with $22.5 \%$ volumetric fraction of nickel particles reached $70{ }^{\circ} \mathrm{C}$, but only needed 20V (36).

Analyzing each series individually, first of all, control specimens (without CNF) could not increase their temperature whichever voltage was applied (only $3{ }^{\circ} \mathrm{C}$ increase was registered with $150 \mathrm{~V}$ ). Electrical resistivity was so high that the current intensity was so low that the current density was not enough to heat the material due to Joule effect.

On the other hand, whichever voltage was selected the behavior regarding temperature increase of pastes with 1 or $2 \% \mathrm{CNF}$ was very similar. Both of them showed higher temperature increases for higher voltages applied. But this temperature changes were almost imperceptible for $50 \mathrm{~V}$ and very low for $100 \mathrm{~V}$ (around $11^{\circ} \mathrm{C}$ ). However, if $150 \mathrm{~V}$ were applied these composites showed temperature increases of $+50^{\circ} \mathrm{C}$ and $+60{ }^{\circ} \mathrm{C}$ with respect to ambient temperature, for $1 \%$ and $2 \%$ CNF dosages, respectively. These maximum temperature values were reached after 3100 and 2100 seconds, respectively, i.e. heating rate was faster as CNF dosage was higher. Once this maximum was surpassed temperature began to decrease slightly, always $30^{\circ} \mathrm{C}$ beyond ambient conditions, and was capable of maintaining it for more than one hour.

Considering only $5 \% \mathrm{CNF}$ pastes specimens, when a $50 \mathrm{~V}$ voltage was applied, temperature was increased by $10{ }^{\circ} \mathrm{C}$, for all conservation conditions (100\% RH or laboratory conditions). Temperature increases of specimens kept in laboratory conditions were always higher than its $100 \%$ RH counterparts. This difference was small if only $50 \mathrm{~V}$ was applied, but increased significantly for $100 \mathrm{~V}\left(+49^{\circ} \mathrm{C}\right.$ vs $\left.+33^{\circ} \mathrm{C}\right)$ and even more for $150 \mathrm{~V}\left(+96{ }^{\circ} \mathrm{C}\right.$ vs $\left.+71{ }^{\circ} \mathrm{C}\right)$. It is worth mentioning that the $+96{ }^{\circ} \mathrm{C}$ increase corresponds to a mean specimen's temperature of $119^{\circ} \mathrm{C}$ and a maximum $138^{\circ} \mathrm{C}$ value, and then the current was cut off for safety concerns.

Finally the linear change in temperature functions with respect to the applied voltage was verified for the 5\% CNF specimens, for both $100 \% \mathrm{RH}$ and laboratory conservation. According to equation 1 the power consumption is directly proportional to 

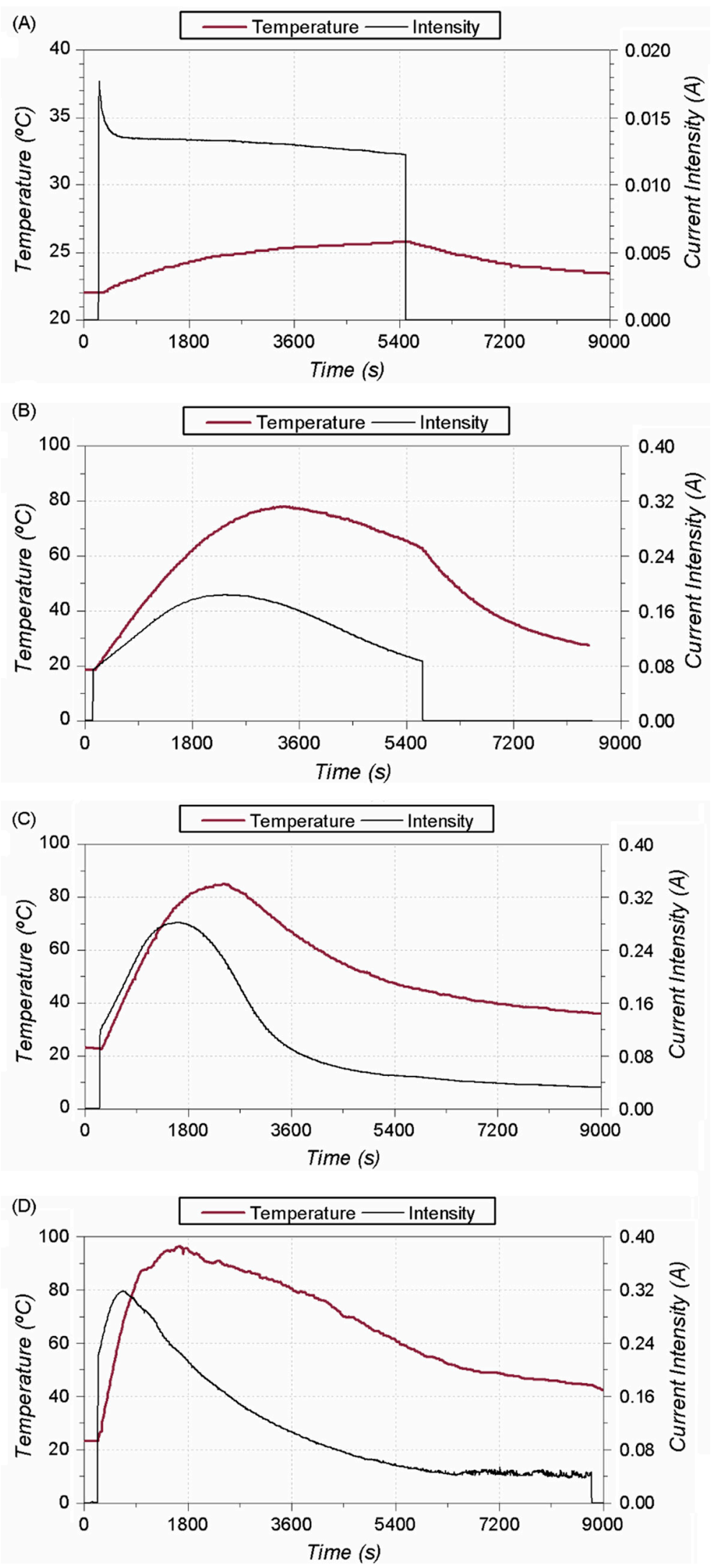

FIGURE 3. Temperature and current intensity versus time for $150 \mathrm{~V}$ self-heating tests of CNF cement paste specimens kept in 100\% RH: (A) $0 \%$ CNF, (B) $1 \% \mathrm{CNF}$, (C) $2 \% \mathrm{CNF}$, (D) $5 \% \mathrm{CNF}$ 


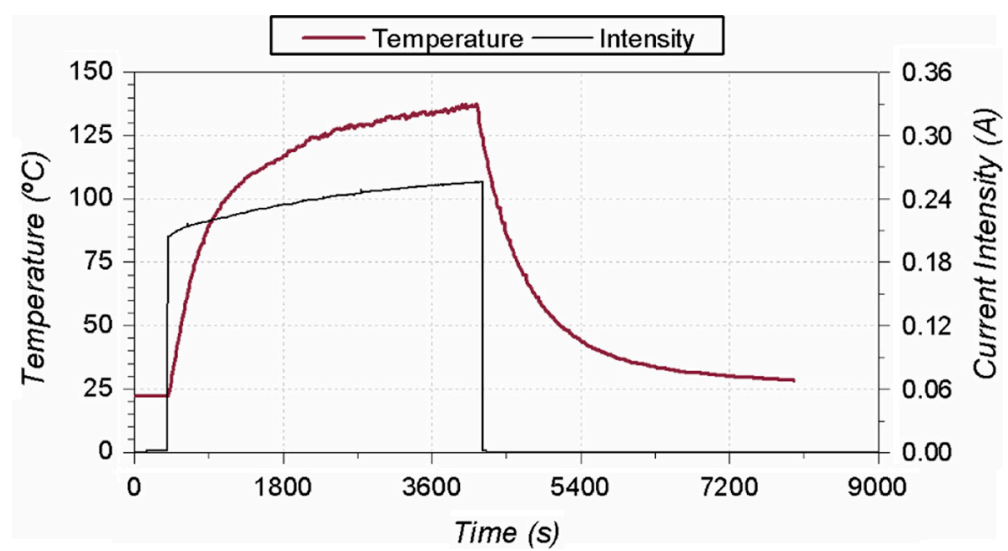

FIGURE 4. $150 \mathrm{~V}$ self-heating test of a 5\% CNF cement paste specimen kept in laboratory conditions.

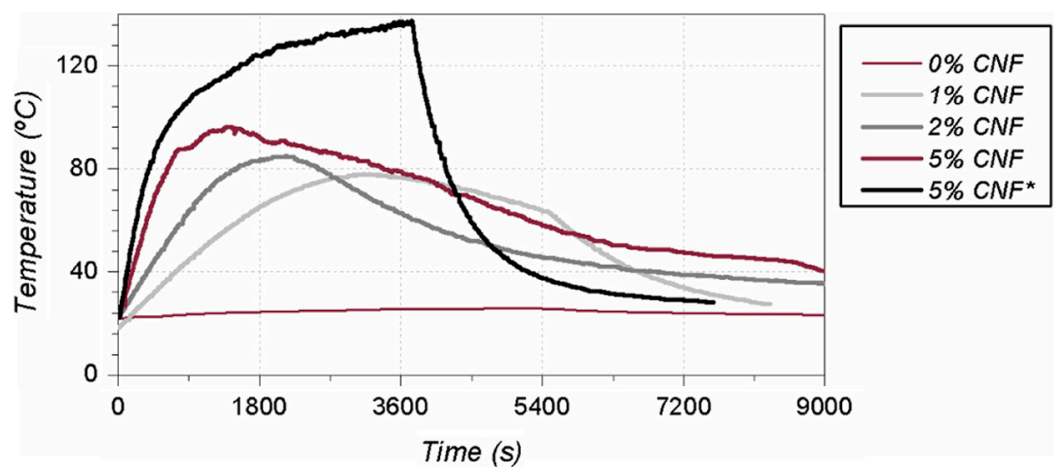

FIGURE 5. Temperature measured at the center point of different CNF cement paste specimens. (*Specimens conserved in laboratory conditions until constant weight).

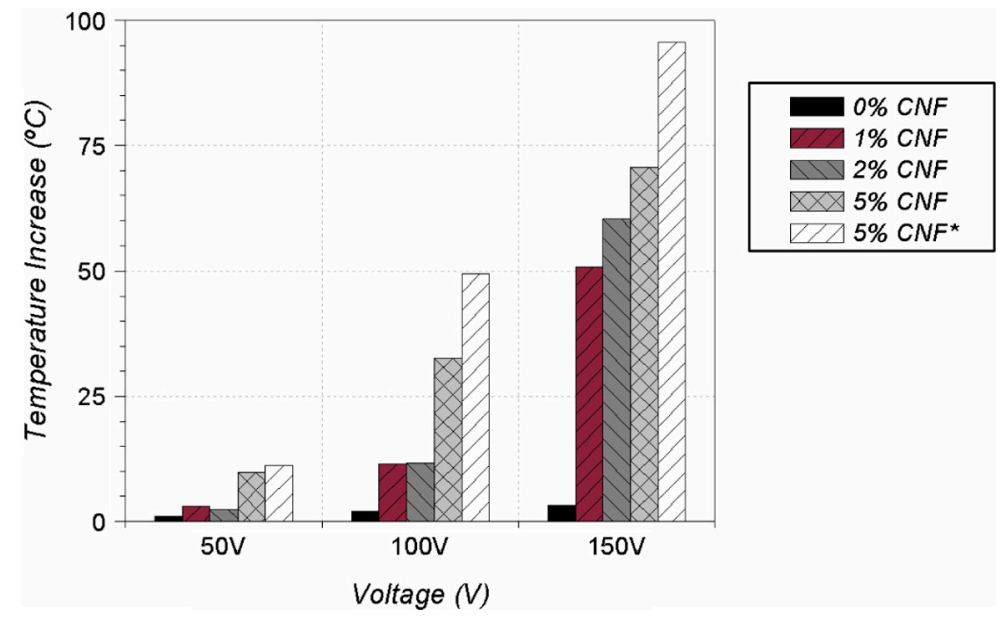

FIgURE 6. Temperature increase versus voltage for each different CNF dosage tested. (*Specimens conserved in laboratory conditions until constant weight).

$\mathrm{V}^{2}$, hence it would be necessary to make voltage as low as possible. If linear regressions are considered, $65 \mathrm{~V}$ will be enough to increase $20^{\circ} \mathrm{C}$ the material's temperature in a real application, limiting therefore the energy cost. The real breakthrough that has been achieved by using $5 \% \mathrm{CNF}$ pastes is their lower electrical resistivity, in comparison to other dosages and casting methods also studied (3).

$$
P=V \cdot I=\frac{V^{2}}{R}
$$


TABLE 3. Initial heating rate for all CNF dosages for $150 \mathrm{~V}$ tests, corresponding to a temperature increase from $20^{\circ} \mathrm{C}$ to $60{ }^{\circ} \mathrm{C}$. $\left({ }^{*}\right.$ Specimens conserved in laboratory conditions until constant weight)

\begin{tabular}{lcc}
\hline CNF dosage & $\begin{array}{c}\text { Heating rate } \\
\left({ }^{\circ} \mathbf{C} / \text { min }\right)\end{array}$ & $\begin{array}{c}\text { Time to increase } \\
\mathbf{+ 4 0}{ }^{\circ} \mathbf{C}(\mathbf{m i n})\end{array}$ \\
\hline $0 \% \mathrm{CNF}$ & - & - \\
$1 \% \mathrm{CNF}$ & 1.6 & 25.2 \\
$2 \% \mathrm{CNF}$ & 2.8 & 14.4 \\
$5 \% \mathrm{CNF}$ & 6.4 & 6.3 \\
$5 \% \mathrm{CNF} *$ & 10.7 & 3.7 \\
\hline
\end{tabular}

\subsection{Maximum heating rates}

In order to study the heating rate, Figure 7 shows Pt100-1 temperature (Figure 1) up to $60^{\circ} \mathrm{C}$ (corresponding to $+35{ }^{\circ} \mathrm{C}$ and $+40{ }^{\circ} \mathrm{C}$ temperature increments) versus time, for all dosages and $150 \mathrm{~V}$ tests. Obviously control specimens, without $\mathrm{CNF}$, were almost unable to increase the temperature, so only about 20 min time have been plotted. Additionally a linear regression function was calculated, whose characteristic parameters are summarized in Table 3. Both heating rates and time necessary to achieve the desire temperature increment are included. Once again, control specimens showed negligible heating rates, in contrast to the $10{ }^{\circ} \mathrm{C} / \mathrm{min}$ heating rate showed by a $5 \% \mathrm{CNF}$ cement paste kept at $100 \% \mathrm{RH}$ (casted as shotcrete). Just like in the previous analysis CNF content can be directly related to the heating rate of CNF pastes. If only 5\% CNF pastes are considered, the better results (faster heating rate) were shown by the laboratory conserved pastes instead of the $100 \% \mathrm{RH}$ conserved composites. The values included in Table 3 are equal to or even higher than other examples found in prior works $(9,36)$, in which the composites with higher heating rates were: i) cement pastes with $0.7 \mathrm{vol} \%$ steel fibers, $3.4^{\circ} \mathrm{C} / \mathrm{min}(9)$; ii) cement pastes with $1 \mathrm{vol} \%$ carbon fibers, $4.6{ }^{\circ} \mathrm{C} / \mathrm{min}$ (9); iii) cement pastes with $37 \mathrm{vol} \%$ graphite powder, $1.6^{\circ} \mathrm{C} / \mathrm{min}(9)$; iv) cement pastes with $12 \mathrm{vol} \%$ nickel particles, $1.5^{\circ} \mathrm{C} / \mathrm{min}$ (36).

\subsection{Current intensity behavior}

The following considers the different electrical current behavior, as they were introduced in Figures 3 and 4, and their relation to CNF dosages. During self-heating tests three different behavior patterns were detected. Figure 8 summarizes all different possibilities in this regard. The particular testing conditions are gathered in the figure's legend, but only a few examples of each behavior are shown.

Behavior type 1, according to Figure 8, was obtained for all control specimens whichever voltage conditions were selected, as well as 1\% and 2\% CNF pastes tested at $50 \mathrm{~V}$; in other words, non-conductive or low conductive composites, tested at low voltages. When the power source, which controlled the fixed voltage, was connected, a peak on the intensity was detected. After this initial peak (around $30 \mathrm{~mA}$ ), due to the high resistivity of the material, the current intensity rapidly decreased and stabilized at $10 \mathrm{~mA}$ approximately. Thus the current density (i.e. intensity per area unit) was not enough to increase temperature by Joule effect.

The second behavior, type 2 , showed a higher initial current peak between 40 and $100 \mathrm{~mA}$, which led to temperature increases around $+12{ }^{\circ} \mathrm{C}$ and $+30^{\circ} \mathrm{C}$ respectively. The main difference is the stability of this test, i.e. both intensity and temperature were quite stable during tests. Cement pastes with $1 \%$ and $2 \% \mathrm{CNF}$ at $100 \mathrm{~V}$, and $5 \% \mathrm{CNF}$ composites at $50 \mathrm{~V}$ (for all conservation conditions) showed this behavior type. Hence type 2 is characteristic of low conductive pastes at medium voltages and more conductive pastes at low voltages. Temperature increments were not very high anyhow.

Finally, behavior type 3 showed initial currents of $100 \mathrm{~mA}$ approximately, which progressively increased up to a maximum 200 or $300 \mathrm{~mA}$ value. Temperatures

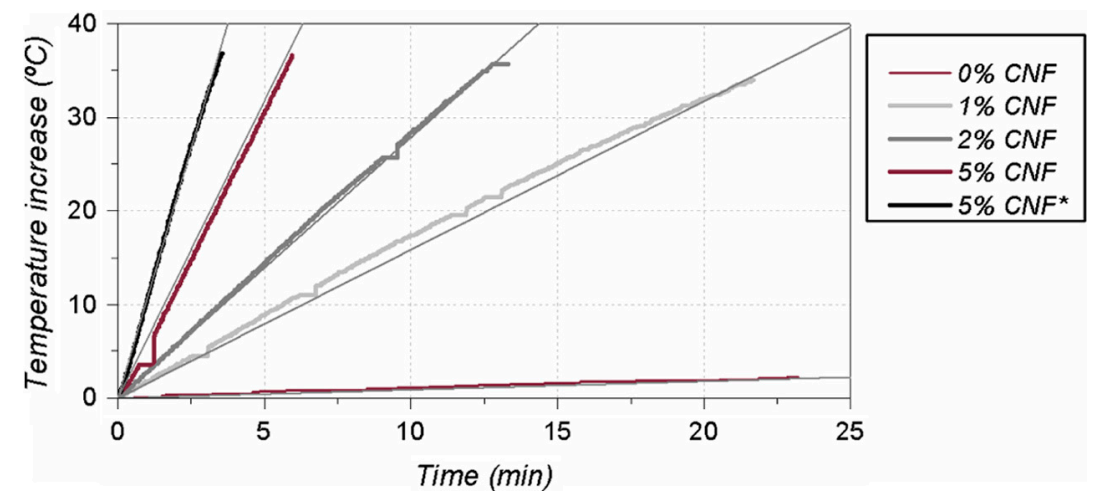

FIGURE 7. Initial temperature increase during the first test minutes for each CNF dosage and $150 \mathrm{~V}$. $(*$ Specimens conserved in laboratory conditions until constant weight). 


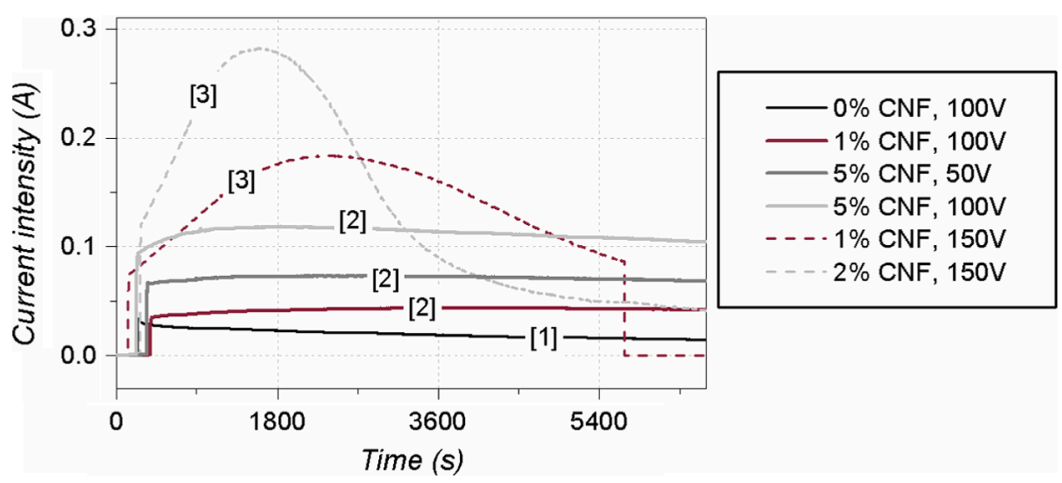

FIGURE 8. Current intensity vs time behavior patterns, monitored during self-heating tests. Three different types have been distinguished.

increased almost $+50{ }^{\circ} \mathrm{C}$ or $+70{ }^{\circ} \mathrm{C}$ this time, and showed similar decreasing rates afterwards. Obviously temperature curves tend to match their current intensity counterparts, i.e. their increases and decreases, with some delay due to the material's thermal inertia. This behavior was only detected for the $150 \mathrm{~V}$ tests with $1 \%$ and $2 \%$ CNF pastes and for 100 and $150 \mathrm{~V}$ with $5 \%$ CNF composites kept in 100\% RH ambient.

The main differences between each behavior type can be summarized as follows:

- If pastes' electrical resistivity was high, the consequent electrical intensity was low and unable therefore to increase the specimen's temperature.

- Increasing the applied voltage between electrodes or decreasing composite's resistivity (with higher $\mathrm{CNF}$ dosage) produced higher current intensities, and in this way temperature could be increased. However, energy was initially wasted to heat the pore interstitial solution in the matrix. Therefore in the cases in which moderate temperatures were reached (around $50{ }^{\circ} \mathrm{C}$ ) both current and temperature remained stable. If the power source's voltage or the specimen's resistivity were enough to increased temperature beyond 50 or $60^{\circ} \mathrm{C}$, most of the interstitial water would evaporate, and the electrical resistivity would therefore be increased, hence reducing the intensity and temperature.

- The water content was lower for $5 \% \mathrm{CNF}$ cement paste kept in laboratory conditions, and so almost all the energy could therefore be transformed into heat in these composites.

To sum up this section, specimen's water content is a very important parameter that should be consequently studied in depth in future researches.

\subsection{Power consumption analysis}

finally a brief study regarding the power consumption differences was made. Figure 9 includes the energy consumption in $\mathrm{kWh}$ that was necessary to increase $10^{\circ} \mathrm{C}$ the initial specimen's temperature for every voltage and CNF dosages tested in this research. Those cases that were unable to heat at least $10{ }^{\circ} \mathrm{C}$ have not been included $(0 \% \mathrm{CNF}$ at all voltages, and 1 and $2 \% \mathrm{CNF}$ at $50 \mathrm{~V}$ ). $5 \% \mathrm{CNF}$ composites kept in laboratory conditions (and casted as shotcrete) showed very low energy requirements slightly higher than $60 \mathrm{Wh}$.

The low energy consumption of these 5\% CNF pastes (after being kept in laboratory conditions) whichever voltage applied, makes them the most suitable cement paste for thermal applications, among all dosages tested in this study.

Voltages used in this research are especially high anyhow. A very strict set of safety measures would be necessary to avoid personal or material damages. Another future line of work should be designed to improve composite's conductivity, hence reducing the voltage necessary in the system, and consequently the current intensity, which is even more dangerous.

\section{CONCLUSIONS}

Cement pastes with different CNF dosages were fabricated, and three different DC fixed voltages applied for testing. After all results have been discussed, the following conclusions can be drawn:

- Control specimens, without any conductive ad mixtures, were incapable of transforming electrical energy into heat, as expected. This material is therefore unsuitable for any application requiring self-heating properties, due to Joule effect, in order to act as heating or deicing elements.

- $1 \%$ and $2 \%$ CNF cement pastes are capable of obtaining high temperature increases but high voltages are required (around 150V). Besides both CNF dosages showed similar behavior in all tests.

- Cement pastes with 5\% CNF addition (by cement mass), casted as shotcrete, were capable of highly increasing their temperature when at 


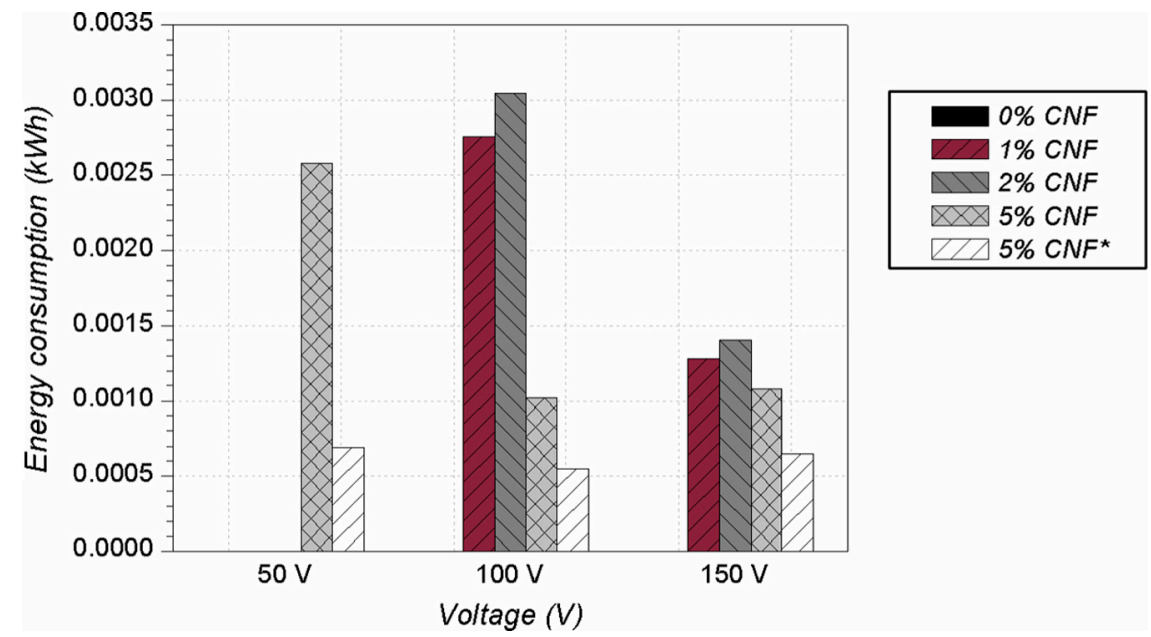

FIGURE 9. Energy consumption versus voltage when the temperature of the center point of each specimen was increased from $20^{\circ} \mathrm{C}$ to $30^{\circ} \mathrm{C}$. ( ${ }^{*}$ Specimens conserved in laboratory conditions until constant weight).

least $65 \mathrm{~V}$ voltages were applied, due to Joule effect. This fact makes this material suitable for thermal applications such as heating element in room conditioning or as a civil infrastructures deicing method. Heating rates up to $10^{\circ} \mathrm{C} / \mathrm{min}$ have been measured, and improvements were observed for lower moisture contents.

\section{ACKNOWLEDGEMENTS}

The authors would like to thank the Spanish Ministerio de Ciencia e Innovación for its financial support (ref: Mat2009-10866).

\section{REFERENCES}

1. Baeza, F.J.; Chung, D.D.L.; Zornoza, E.; Andión, L.G.; Garcés, P. (2010) Triple percolation in concrete reinforced with carbon fiber. ACI Mater. J., 107 [4], 396-402.

2. Chung, D.D.L. (2002) Electrical Conduction Behavior of Cement-Matrix. Composites. J. Mater. Eng. Perform., 11 [2], 194-204. http://dx.doi.org/10.1361/105994902770344268.

3. Galao, O. (2012) Matrices cementicias multifuncionales mediante adición de nanofibras de carbono. Ph.D. Thesis, University of Alicante, Spain.

4. Chung, D.D.L. (2001) Functional Properties of CementMatrix Composites. J. Mater. Sci., 36, 1315-1324. http:// dx.doi.org/10.1023/A:1017522616006.

5. Yehia, S.; Tuan, C. (1999) Conductive concrete overlay for bridge deck deicing. ACI Mater. J., 96 [3], 382-390.

6. Yehia, S.; Tuan, C.; Ferdon, D.; Chen, B. (2000) Conductive concrete overlay for bridge deck deicing: mixture proportioning, optimization, and properties. ACI Mater. J., 97 [2], $172-181$.

7. Chung, D.D.L. (2001) Cement-Matrix Composites for Thermal Engineering. Appl. Therm. Eng., 21, 1607-1619. http://dx.doi.org/10.1016/S1359-4311(01)00043-6.

8. Chung, D.D.L. (2001) Materials for thermal conduction. Appl. Therm. Eng., 21, 1593-1605. http://dx.doi.org/ 10.1016/S1359-4311(01)00042-4.

9. Wang, S.; Wen, S.; Chung, D.D.L. (2004) Resistance heating using electrically conductive cements. Adv. Cem. Res., 16, 161-166. http://dx.doi.org/10.1680/adcr.2004.16. 4.161.
10. Tuan, C. (2004) Electrical resistance heating of conductive concrete containing steel fibers and shavings. ACI Mater. J., 101 [1], 65-70.

11. Chung, D.D.L. (2004) Self-heating structural materials. Smart Mater. Struct., 13 [3], 562-565. http://dx.doi.org/ 10.1088/0964-1726/13/3/015.

12. Tuan, C.; Yehia, S. (2004) Evaluation of Electrically Conductive Concrete Containing Carbon Products for Deicing. ACI Mater. J., 101 [4], 287-293.

13. Chang, C.; Ho, M. Song, G.; Mo, YL.; Li, H. (2009) A feasibility study of self-heating concrete utilizing carbon nanofiber heating elements. Smart Mater. Struct., 18 [12], 1-5. http://dx.doi.org/10.1088/0964-1726/18/12/127001.

14. Zhao, H.M.; Wu, Z.M.; Wang, S.G.; Zheng, J.J.; Che, G.J. (2011) Concrete pavement deicing with carbon fiber heating wires. Cold Reg. Sci. Technol., 65 [3], 413-420.

15. Li, H. Zhang, Q; Xiao, H. (2013) Self-deicing road system with a CNFP high-efficiency thermal source and MWCNT/ cement-based high-thermal conductive composites. Cold Reg. Sci. Technol., 86, 22-35. http://dx.doi.org/10.1016/j. coldregions.2012.10.007.

16. Baeza, F.J.; Zornoza, E.; Andión, L.G.; Ivorra, S.; Garcés, P. (2011) Variables affecting strain sensing function in cementitious composites with carbon fibers, Comput. Concrete, 8 [2], 229-241. http://dx.doi.org/10.12989/cac. 2011.8.2.229.

17. Chen, P.W.; Chung, D.D.L. (1996) Concrete as a new strain/ stress sensor. Compos. Part B-Eng., 27B [1], 11-23. http:// dx.doi.org/10.1016/1359-8368(95)00002-X.

18. Zornoza, E.; Catalá, G.; Jiménez, F.; Andión, L.G.; Garcés, P. (2010) Electromagnetic interference shielding with Portland cement paste containing carbon materials and processed fly ash. Mater. Construcc., 60 [300], 21-32. http://dx.doi.org/ $10.3989 / \mathrm{mc} .2010 .51009$

19. Zornoza, E.; Galao, O.; Baeza, F.J.; Garcés, P. (2012) Electromagnetic interference shielding of cement pastes with carbon nanofibers. In NICOM4 Nanotechnology in Construction, Proceedings of the 4th International Symposium on Nanotechnology in Construction, Agios Nikolaos, Creta.

20. Yang, Y.; Gupta.; M.C.; Dudley, K.L. (2007) Towards costefficient EMI shielding materials using carbon nanostructurebased nanocomposites. Nanotechnology, 18 [345701], 4.

21. Pérez, A.; Climent, M.A.; Garcés, P. (2010) Electrochemical extraction of chlorides from reinforced concrete using a conductive cement paste as an anode, Corros. Sci., 52 [5], 1576-1581. http://dx.doi.org/10.1016/j.corsci.2010.01.016.

22. del Moral, B.; Galao, O.; Antón, C.; Climent, M.A.; Garcés, P. (2013) Usability of cement paste containing carbon nanofibers as an anode in electrochemical chloride extraction from 
concrete. Mater. Construcc., 63 [309], 39-48. http://dx.doi.org/ 10.3989/mc.2012.03111

23. Garcés, P.; Carmona, J.; Galao, O.; Zornoza, E.; Climent, M.A. (2012) Carbon nanofibre cement paste as anode for electrochemical chloride removal. In NICOM4 Nanotechnology in Construction, Proceedings of the 4th International Symposium on Nanotechnology in Construction, Agios Nikolaos, Creta.

24. Bertolini L.; Bolzoni F.; Pastore T.; Pedeferri P. (2004) Effectiveness of a conductive cementitious mortar anode for cathodic protection of steel in concrete. Cement Concrete Res., 34 [4], 681-694. http://dx.doi.org/10.1016/j.cemconres. 2003.10.018

25. Xu, J.; Yao, W. (2009) Current distribution in reinforced concrete cathodic protection system with conductive mortar overlay anode. Constr. Build. Mater., 23 [6], 2220-2226. http://dx.doi.org/10.1016/j.conbuildmat.2008.12.002.

26. Alcaide, J.S.; Alcocel, E.G.; Puertas, F.; Lapuente, R.; Garcés, P. (2007) Carbon fibre-reinforced, alkali-activated slag mortars. Mater. Construcc., 57 [288], 33-48.

27. Garcés, P.; Zornoza, E.; Alcocel, E.G.; Galao, O.; Andión, L.G. (2012) Mechanical properties and corrosion of CAC mortars with carbon fibers. Constr. Build. Mater., 34, 91-96. http://dx.doi.org/10.1016/j.conbuildmat.2012.02.020

28. Chung, D.D.L. (2004) Cement-Matrix Structural Nanocomposites. Met. Mater. Int., 10 [1], 55-67. http://dx.doi.org/ $10.1007 / \mathrm{BF} 03027364$

29. Coleman, J.N.; Khan, U.; Blau, W.J.; Gun'ko, Y.K. (2006) Small but strong: A review of the mechanical properties of carbon nanotube polymer composites. Carbon, 44 [9], 1624 1652. http://dx.doi.org/10.1016/j.carbon.2006.02.038

30. Wang, J.G.; Fang, Z.P.; Gu, A.J.; Xu, L.H.; Liu, F. (2006) Effect of amino-functionalization of multi-walled carbon nanotubes on the dispersion with epoxy resin matrix.
J. Appl. Polym. Sci., 100 [1], 97-104. http://dx.doi.org/ 10.1002/app. 22647

31. Tibbetts, G.G.; Lake, M.L.; Strong, K.L.; Rice, B.P. (2007) A review of the fabrication and properties of vapor-grown carbon nanofiber/polymer composites. Compos. Sci. Technol., 67 [7-8], 1709-1718. http://dx.doi.org/10.1016/j. compscitech.2006.06.015

32. Marrs, B.; Andrews, R.; Pienkowski, D. (2007) Multiwall carbon nanotubes enhance the fatigue performance of physiologically maintained methyl methacrylate-styrene copolymer. Carbon, 45 [10], 2098-2104. http://dx.doi.org/ 10.1016/j.carbon.2007.05.013.

33. Abu Al-Rub, R.K.; Tyson, B.M. (2010) Assessment the Potential of Using Carbon Nanotubes Reinforcements for Improving the Tensile/Flexural Strength and Fracture Toughness of Portland Cement Paste for Damage Resistant Concrete Transportation Infrastructures. Technical Report No. SWUTC/10/476660-00011-1, http://ntl.bts.gov/lib/38000/ 38500/38505/476660-00011-1.pdf.

34. Baeza, F.J.; Galao, O.; Zornoza, E.; Garcés, P. (2013) Multifunctional cement composites strain and damage sensors applied on reinforced concrete (RC) structural elements. Materials, 6, 841-855. http://dx.doi.org/10.3390/ ma6030841.

35. Galao, O.; Zornoza, E.; Baeza, F.J.; Bernabeu, A.; Garcés, P. (2012) Effect of carbon nanofiber addition in the mechanical properties and durability of cementitious materials. Mater. Construcc., 62 [307], 343-357. http://dx.doi.org/10.3989/ mc.2012.01211.

36. Zhang, K.; Han, B.; Yu, X. (2011) Nickel particle based electrical resistance heating cementitious composites. Cold Reg. Sci. Technol., 69, 64-69. http://dx.doi.org/10.1016/j. coldregions.2011.07.002. 